\title{
Corporate governance as custodianship of the business model
}

\author{
Michael Page ${ }^{1}$ Laura F. Spira ${ }^{2}$
}

Published online: 21 March 2016

(C) The Author(s) 2016. This article is published with open access at Springerlink.com

\begin{abstract}
Recently businesses have been encouraged to discuss their business models in their annual reports as a means of communicating their future intentions to readers of their financial statements. At the same time, corporate governance has continued to be a focus of attention. In this paper we set out the view that a useful way of regarding corporate governance is that of custodianship of the business model-by which we mean that the directors are responsible for sustaining and developing a company's business model. A comparison of corporate governance and the activities required to sustain and develop the business model shows them to be essentially the same. A business model view has the advantage that it unifies the compliance and monitoring aspects of governance with the advisory and strategysetting roles of directors, roles that have sometimes been seen as conflicting. Viewing corporate governance from a business model perspective highlights aspects of board responsibilities that are not explicitly recognised in the UK Corporate Governance Code and may have been neglected in the prevailing emphasis on compliance, but which are intimately connected to both network relationships and corporate culture which are now becoming a source of concern.
\end{abstract}

Keywords Corporate governance - Business model - Network relationship . Business culture ethics and values

Michael Page

Mike.Page@port.ac.uk

1 University of Portsmouth, Portsmouth, UK

2 Oxford Brookes University, Oxford, UK 


\section{Introduction}

Although the last two decades have seen an increasing concern about issues of corporate governance and the introduction of extensive codes and guidance to address these issues, debate continues about the role and effectiveness of the board of directors. Scandals, such as Volkswagen's cheating on emissions testing and Libor rigging at Barclays and other banks, have raised questions of directors' responsibility for operational matters and ethical behaviour that seem peripheral to corporate governance as it commonly characterised. At the same time, companies are being required to describe their 'business models' in their annual reports and some accounting measurements are based on them. In its draft conceptual framework, the IASB (2015) believes that 'business activities' (its term for the business model) affect the unit of account, accounting measurement, and presentation and disclosure. The International Integrated Reporting Council (IIRC), the Enhanced Disclosure Task Force of the Financial Stability Board, the European Financial Reporting Advisory Group and other bodies all draw on the business model concept (Nielsen and Roslender 2015).

Considerable effort has been expended, and continues to be, on definitional debate about what constitutes corporate governance and what business models are.

The report of the Cadbury Committee in 1992 characterised corporate governance as 'the system by which businesses are directed and controlled', a definition widely adopted but framed within the narrow remit of the Committee which was related to the financial aspects of corporate governance The definition in the 2004 OECD principles of corporate governance offered a different perspective: "Corporate governance involves a set of relationships between a company's management, its board, its shareholders and other stakeholders." However, the Cadbury Code "comply or explain" approach to corporate governance disclosure, which is now firmly embedded in regulatory structures, retains a central focus on the accountability role of board members.

A broad characterisation of business models is 'how businesses create value' but a substantial literature has developed elaborating alternative views. There is a need to distinguish between business models and how they are represented, although not all scholars are able to maintain the distinction. For us, the model is a system that comprises the activities of the business, its relationships with stakeholders and its tangible and intangible assets and liabilities. The model can be represented in different ways such as a diagram, a spreadsheet, a set of equations or a narrative. Such representations are by their nature incomplete and focus on particular aspects of the business's activities and relationships.

For our purposes, precise definitions are unimportant; we argue that the use of a business model perspective, based on key tasks which would be readily accepted as fundamental to the operation of any business model, can highlight aspects of the board's role which, while widely viewed as central to board responsibility, have not been clearly articulated in the UK corporate governance framework.

The paper first outlines some salient features of corporate governance and of the business model concept and then identifies and compares the activities of corporate 
boards associated with corporate governance and those activities concerned with sustaining and developing the business model. This comparison shows that they are essentially the same and supports the argument that viewing corporate governance through a business model lens provides a new and helpful approach to discussing board responsibilities.

\subsection{Corporate governance}

Concern with the issues that now broadly fall within the scope of corporate governance dates back to the middle of the twentieth century when the term first appeared in legal and management discourse (Spira and Slinn 2013: xx).

Ocasio and Joseph (2005) used content analysis techniques to map the development of the vocabulary of corporate governance in the United States from 1972 to 2003 , noting that:

...the category of activities directly referred to as corporate governance shifted from an initial focus on business and public policy and corporate social responsibility to a concern with board organization, executives and decision making. (Ocasio and Joseph 2005: 172)

Such a shift was consistent with the apparent inadequacy of accountability mechanisms highlighted by financial scandals, which resulted in attempts to realign board structures to emphasise directors' responsibilities with regard to internal control. However, this shift focused attention on compliance and internal structures and processes, rather than the wider social context within which companies exist.

The focus on accountability within the Cadbury Code was challenged by critics who believed that this could stifle enterprise (Spira 2001) as the Hampel Committee's revision of the Code made clear:

The importance of corporate governance lies in its contribution both to business prosperity and to accountability. In the UK the latter has preoccupied much public debate over the past few years. We would wish to see the balance corrected...the emphasis on accountability has tended to obscure a board's first responsibility-to enhance the prosperity of the business over time. (Hampel Committee 1998: 7)

Whether the changes in board structure and composition, such as the establishment of audit committees and the increased number of independent nonexecutive directors (NEDs), have contributed to any significant improvement in corporate governance remains a moot point: there is little firm evidence to demonstrate that they have been successful in improving oversight. Perhaps implicitly acknowledging the ineffectiveness of such remedies, a further shift is now taking place: recent concerns have been framed as deficiencies in corporate culture. ${ }^{1}$

\footnotetext{
1 See for example, the Financial Reporting Council's Culture Project (https://www.frc.org.uk/Our-Work/ Codes-Standards/Corporate-governance/Culture-Project.aspx) and Grant Thornton's 2015 report "Corporate Governance: tone from the top" http://www.grantthornton.global/en/insights/articles/corporategovernance-2015/?utm_source=google\&utm_medium=website\&utm_campaign=Corporate\%20governance $\%$ 202015.
} 
From the time of the Cadbury Committee's report, conceptions of "good" corporate governance have been predicated on the assumption that governance and management should be firmly separated. The roles of chairman and CEO should not be held by the same individual (provision A.2.) and recent iterations of the UK Corporate Governance Code prescribe that a CEO should not go on to become chairman of the same company (provision A.3.1). Yet, paradoxically, the role of the independent NED on a unitary board carries the same responsibilities as an executive director but with the added requirement of oversight.

One of the earliest writers on corporate governance, Bob Tricker, classified board activities into conformance and performance.

\begin{tabular}{lll}
\hline & Conformance activities & Performance activities \\
\hline Outward looking & Accountability & Strategy formulation \\
Inward looking & Supervising executive activities & Policy making \\
& Past/present focus & Future focus \\
\hline
\end{tabular}

\section{(Tricker 2012: 45).}

While this is a convenient way to summarise the focus of board activities, the four very broad categories suggest that there may be overlaps in practice: in particular, the role of the independent non-executive director appears to straddle both conformance and performance. Ezzamel and Watson (1997) argued that this tension in the NED role was problematic and could not be sustained in practice, thus preventing the Cadbury proposals for increasing the monitoring role of NEDs from being effective. However, Roberts et al. (2005) explored the role in their work supporting the Higgs Review of non executive directors and concluded that in practice NEDs viewed their strategic contribution to the board and their oversight activities as complementary: "Far from being an impediment to non-executive independence, involvement and engagement inform its exercise" (S17).

While there is little evidence to tell us how much time boards typically spend on each category of these four activities, it is quite possible that the expectation that independent NEDs will exercise a significant monitoring role, coupled with changing board structures over the last decade, would increase the focus of board attention on compliance. Many boards are now predominantly non executive, with the CEO and CFO the only executive members (described as "CEO-only" boards by Joseph et al. 2014) and the main link to a separate executive management group. While it appears that the boundary between corporate governance and management is firmly established in this structure, published reports provide little indication of how these two groups interact to undertake their roles.

In the next section we consider these activities in more detail by setting out the key board tasks emphasised in current corporate governance requirements, and reflecting on how they might be considered to sustain and develop the business model. We then compare them to tasks which have been identified by scholars and policy makers as key to sustaining and developing the business model. 


\section{Business models}

\subsection{The nature of business models}

Although we have said precise definition of business models is unimportant for this paper, it is important to clarify what kind of a phenomenon 'business models' are. If we consider a broad definition of a business model such as 'the way a company creates value', does this comprise a set of physical and intangible resources together with ways of doing business, relationships with stakeholders and other things, or is it a description of these things in some form? Different scholars and bodies disagree. This matters because when an organisation describes its business model, the description may be different in kind depending on whether it is describing a set of resources, etc. or whether it is describing a description of these things. To use an analogy, a description of a vase of flowers is different from a description of a painting of a vase of flowers. The painting and the vase of flowers are different in kind. Similarly, a set of resources, etc. is different from a description of them (in some form such as a diagram). This kind of ontological distinction is often glossed over in speech but in scholarly discussion more precision is required and it is important to avoid making category errors, when, for example, Venn diagrams are constructed, so that they include only sets of items of the same kind.

To take the definitions of business models cited by Zott et al. (2011: 1024), these include

- An architecture (which includes descriptions)

- A depiction (of the content, structure and governance of transactions) but also a 'system of interdependent activities'

- A 'heuristic logic'

- Stories

- A 'concise representation of an interrelated set of variables'

- Four interlocking elements (customer value proposition, profit formula, key resources, key processes)

- A 'reflection of realized strategy'

- An articulation of 'the logic, the data and other evidence that support a value proposition for the customer...'

Most of these definitions are representations of some kind but they differ according to the kinds of things they are representing. Some of the definitions are of actual resources, processes and relationships. If business models are some kind of representation or depiction of underlying resources, processes and relationships, a phrase is needed to describe the phenomenon that results when these things operate together and it is generally also called the 'business model'. As for example the IIRC does: 'The term business model is defined herein as "the chosen system of inputs, business activities, outputs and outcomes that aims to create value over the short, medium and long term"' IIRC (2013: 1). It appears that scholars, regulators and practitioners use the phrase to mean both the phenomenon and its 
representation. As noted above for present purposes we characterise a business model as a system that comprises the activities of the business, its relationships with stakeholders and its tangible and intangible assets and liabilities.

Regarding a business model as a description without reference to some underlying substance conceals the possibility of dissonance with reality. There is a need to distinguish between business models: (1) that the board would like the business to have (the intended model); (2) business models as they happen (the emergent model); and, (3) business models as described by the company in public (the declared model). The three overlap (in most cases), but the areas of difference may be at least as interesting as the common ground.

There can be at least three important differences:

The intended model versus the emergent model The board may fail to achieve its intentions; there may be a misunderstanding of external and internal factors operating on the business; external factors may change.

The intended model versus the declared model The business may make incomplete or misleading disclosures about its model for proprietary reasons or because its model depends on misleading one or more stakeholders; disclosures about the business model may have been delegated without proper review of results to junior staff or third parties who do not understand the model, or who, for example, subordinate accuracy of disclosure to a neat diagram.

The emergent model versus the declared model The way the business is creating value may be misunderstood or, as above, the declared model is incomplete or misleading, or disclosures have been delegated.

Review of listed companies' business model narratives quickly shows numerous examples of disclosures which appear meaningless, or which subsequent events prove to be unrepresentative of events as they were unfolding (Page 2014).

\subsection{Business models and value}

For the UK Corporate Governance Code the business model is 'the basis on which the company generates or preserves value' whereas the IASB does not define the term business model (which is used in IFRS 9) but in its statement of management commentary (see "Appendix") refers to 'the entity's structure and how it creates value'. 2

The various descriptions of models have much in common with Wilson and Chua's (Wilson and Chua 1993: 23) depiction of the organisation as a 'transformer of contributions' from various stakeholders. An adapted version of this is set out at Table 1. Each group of stakeholders needs to be given sufficient inducement to maintain their contribution to the organisation. The value created in excess of the minimum stakeholder rewards to maintain viability ('organisational slack' or 'value surplus') is allocated among the participants. Value creation is enabled by an organisation's 'value proposition'-the combination of products and services that provides customers, and possibly other stakeholders, with a consumer surplus and

\footnotetext{
${ }^{2}$ Replacing a previous wording of the 'entity's structure and its economic model' in the Exposure Draft of the document.
} 


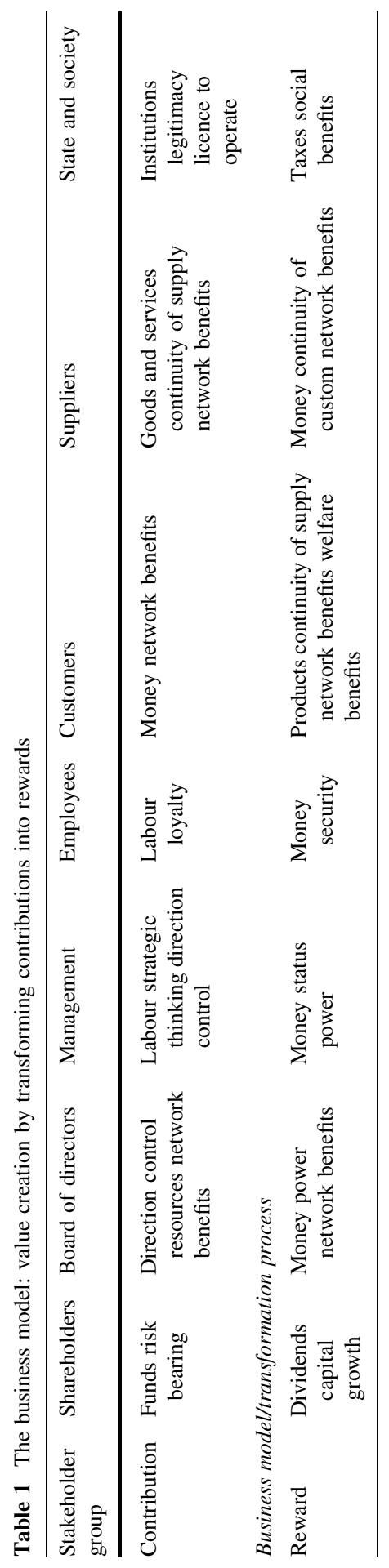


makes them willing to make payments or other contributions. So, for example, the value proposition of a cheap printer and relatively expensive ink may attract a lot of customers and generate more value for the supplier and its partners than pricing each at conventional prices.

Haslam et al. (2015) also conceptualise business models using stakeholder theory in order to critique the capital provider-focussed approach to financial reporting adopted by the IASB (2015: 22). They consider both the size of the 'value-pie' created by the business model and the proportion of value captured by the organisation.

Nielsen and Roslender (2015) survey some of the different characterisations and conclude that while some commentators refer only to value creation, others discuss both value creation and also value capture-how value is captured by the business and transmitted to shareholders. Accounting scholars have tended to focus on how value is measured and deemed available for distribution to shareholders (realisation) (Beattie and Smith 2013).

A key feature of the concept of business models is the role played by networks. Networks are coalitions of long term stakeholders which not only undertake mutually beneficial transactions but may also build up knowledge and knowhow that provides long term competitive advantage because of the difficulty that competitors would have in replicating the relationships. Value creation is a systemic property as it arises from the firm's resources and the properties of the network of stakeholders (Zott et al. 2011).

Value captured is the value surplus held within the business or distributed to shareholders. In this view, the business model becomes the transformation process whereby stakeholder inputs are returned as rewards.

It should not be assumed that organisations are always as successful in capturing value as naïve economic theory would suggest. UK Premier League football clubs are a notable case in point: the value created through gate money and tv deals has largely been appropriated by star players rather than being retained by clubs. In the USA, sports people, although very well paid, have not been so successful in capturing the value created by, for example, American football. Similarly in banks and other financial institutions large parts of value are diverted to the bonus pool for a few employees rather than to shareholders.

This transformation process view of the organisation has similarity with the idea of the organisation as a nexus or 'network of contracts' (Jensen and Meckling 1976) but whereas the nexus of contracts formulation has been used to argue that some organisations are ownerless and corporate responsibility illusory, we argue that, by viewing the role of the board as custodians of the business model/transformation process, corporate responsibility is enhanced rather than diminished.

Strategic planning is usually conceived of as hierarchical, linear and static. The process proceeds from Mission to Objectives to Identification of Options to Selection of Options to Implementation (see for example Stoner and Wankel 1986: 124; Steiner and Miner 1982: 109). By contrast business model design is cyclical, dynamic, path dependent and evolutionary (Teece 2010; Demil and Lecocq 2010). 
Beattie and Smith (2013) describe the business model concept as 'holistic, multilevel, boundary-spanning and dynamic'. Whereas strategy is essentially staticorganisations move from one set of strategies to another as circumstances changebusiness models are dynamic in the sense that models incorporate the need to change strategy in order to maintain competitive advantage.

For Zott et al. (2011), business models form a new unit of analysis, or a different 'chunking' (Hofstadter 1980: 285 et seq) of concepts that can give rise to useful insights.

Having outlined some important aspects of the business model concept as discussed by scholars and regulators, in the next section we draw on the UK corporate governance framework to identify current characterisations of board responsibility.

\section{Key tasks}

In this section we set out the key tasks of corporate governance as characterised by the UK Corporate Governance Code (UKCGC, 2014) and compare these with the key tasks entailed in sustaining and developing the business model.

The Key Principles (KPs) of the UKCGC are mainly concerned with how the board manages itself but the elaboration of those principles explains more about the tasks of boards in directing and controlling the business.

The following list shows the tasks of the board so far as UKCGC (2014) is concerned.

\subsection{The board's role in key corporate governance tasks}

\section{Conformance}

- Establishing culture value and ethics (Preface §4)

- Maintaining sound risk management and internal control systems (KP C 'Accountability')

- Meeting information needs of investors and engaging with shareholders (KP C 'Accountability' and KP E 'Relations with shareholders') Explaining the business model (SP C.1.2)

- Aligning executive remuneration with long term success (KP D 'Remuneration')

- Maintaining an effective board. (KP A 'Leadership', KP B 'Effectiveness') Reviewing management performance and that of the board and individual directors (SP B6)

\section{Performance}

- Setting strategic aims (SP A1). Constructively challenging and helping develop proposals on strategy (SP A4)

- Determining risk appetite in achieving strategic objectives (KP C 'Accountability') 
- Ensuring adequate financial and human resources (SP A1). Overseeing senior appointments (SP B2)

$(\mathrm{KP}=$ Key Principle, $\mathrm{SP}=$ Supplementary Principle in UKCGC $)$.

The list above demonstrates that although corporate governance is sometimes narrowly regarded as confined to monitoring and control of management's actions in order to ensure that they are in the best interests of stakeholders, a much wider set of activities is now comprised by governance, even in the UKCGC. In their Department of Trade and Industry sponsored review of UK corporate governance Filatochev et al. (2006: 16) identify four functions of the board: monitoring and control; strategic advice; network relationships; and, resource acquisition (where, in the terms of resource dependency theory, 'resources' can include network relationships). Comparing this categorisation to that of Tricker above emphasises the more recent focus on the importance of the board's role with regard to external relationships.

\subsection{Key business model tasks}

There is little previous scholarship on the role of the Board relative to a firm's business model. There is a considerable volume of strategic management literature but we have found nothing that adopts a business model approach to the responsibilities of the board. To undertake an analysis, we have drawn from different sources to derive our own synthesis of the activities necessary for a board to sustain and develop the organisation's business model. The components of the business model that have been identified are resources (physical, intangible and human), relationships and a proposition for the creating and capture of value. At any point in time, much of the task of management is to sustain and control these components. Physical and intangible resources need to be safeguarded maintained and replenished and human resources need to be motivated and controlled. Relationships with external stakeholders need to be maintained and enhanced and the value proposition needs to be monitored, evaluated and 'tweaked'.

Because business models are dynamic, sustaining activities and developmental ones are intermingled (Osterwalder et al. 2005) but the role of the board needs to be forward-looking to see what changes are needed to adapt the value proposition (and hence the required resources and relationships) to anticipated changes in the business environment. One way of conceptualising this is to look to the strategic role of the board, but another is to look at it in terms of business models. The business model perspective is more holistic and continuous than a strategic view.

\subsection{The board's role in sustaining and developing the business model: key tasks sustaining the BM}

- Overseeing management control systems (see e.g., Merchant and Van der Stede 2012)

- Personnel controls including cultural and ethical values

- Internal control systems including results and action controls

- Risk measurement and control 
- Ensuring provision of physical, financial, human and other resources (IIRC 2013)

- Maintaining key relationships with stakeholders

- Monitoring and reacting to the impact of internal and external developments on the value proposition (Johnson et al. 2008). Sustaining competitive advantage (Teece 2010)

\subsection{Developing the BM (Demil and Lecocq 2010)}

- Ensuring provision of resources for investment

- Overseeing development of 'competences'

- Reviewing changes to the value proposition

- Overseeing internal and external organisation changes

- Reviewing and controlling revenues and costs

Langfield Smith (2005) reviews the extent to which management control is dependent on business strategy and identifies the Balanced Scorecard (Kaplan and Norton 1996) as a development that explicitly ties performance measurement and control to a company's business model. The extensive literature on control and strategy emphasises the need to coordinate management control systems with strategy and management control systems must therefore have a key role in sustaining business models. Merchant and Van der Stede (2012) divide controls into results, action and personnel controls and, although other authors have sliced things differently, this is a convenient classification.

From an economic perspective the problem of value creation is bound up with creating a sustainable competitive advantage - the source of economic rents. There are various routes open to achieving this by ensuring that competitors cannot replicate the firm's business model. This can be achieved for example by patents, secret know-how, brand investment or cementing relationships. Maintenance of the advantage requires continual monitoring and investment of time and resources. A further route to sustaining competitive advantage is perpetual innovation in the value proposition and the business model. This process is risky, but in most industries inevitable, since competitors' innovations will eventually erode competitive advantage maintained in other ways. One of the dangers is that innovation can make existing products, services and ways of doing business less desirable and thus cannibalise a firm's existing business model. For example, introduction of an online shopping channel may take business away from a firm's bricks and mortar stores. Successful distance learning modules may reduce demand for a university's face to face delivery of courses. ${ }^{3}$

Despite the explicitly dynamic nature of business models, the process of designing them is often described in the same top down static mode as strategy

\footnotetext{
3 It may be remarked that the face to face delivery mode is a remarkable business model for education that has survived for over a thousand years and innovations such as printing and distance learning seem not to have reduced demand.
} 
development (e.g., Zott and Amit 2010). A more evolutionary perspective is taken in the 'transformational review' of Demil and Lecocq (2010) which addresses the question of how models evolve. They suggest that successful business models are seldom conceived fully formed and are the result of a process of refinement and development. In Demil and Lecocq's framework, a business model has components: value proposition; resources (physical and human) and competences; and organisation (including external relationships). The combination of the components generates revenues and costs. Developing the business model therefore entails changes to the components either singly or in combination.

\section{Comparing the board's role in corporate governance tasks and in sustaining and developing the business model}

The two summaries above show very clear parallels: they both require

- Ensuring provision of physical, intangible and human resources

- Informing investors and maintaining relations with shareholder

- Establishing culture values and ethics

- Maintaining sound risk management and internal control systems

It is clear that a company cannot achieve objectives or operate its business model effectively without adequate resources and oversight of provision of resources is implicit in both governance and business model approaches. Informing investors is explicit in the UKCGC but is included in maintaining key relationships with stakeholders. Neither list gives great prominence to establishing culture, values and ethics although recent events such as the Volkswagen scandal may cause regulators to concentrate on it more (Anderson 2015) and there is already evidence of this in the FRC project mentioned in footnote 2. The reasons for paying attention to culture may differ according to the theory of the firm adopted. For example, for agency theorists, culture, values and ethics may be a convenient and effective control mechanism that helps prevent opportunistic behaviour, whereas for people taking a stakeholder view of the firm, culture, values and ethics are needed to give proper weight to the rights and needs of the different stakeholder groups.

Risk management and internal control systems provided an early stumbling block for the development of corporate governance codes (Spira and Page 2003), but it is now clear that maintaining management control is a responsibility of the board. Similarly, although writers on business models have tended to concentrate on definitional, classification and design issues, risk and management control are activities implicit in the implementation of business models.

There are, however, two important ways in which the approaches seem to differ:

- Setting strategic aims and overseeing strategy

- Maintaining external relationships 
While many directors might give strategy setting a high priority in any list of functions, it is not flagged as a main principle of governance by UKCGC, although it is included as a supplementary principle. In the business model literature, strategy formation is not usually identified as a separate activity because, as noted previously, the business model approach bundles functions that include strategy formation differently. It is one of the virtues of the business model approach that it resolves uncertainty about the board's role in relation to strategy.

The UKCGC does not require directors to take responsibility for relationships with stakeholders other than shareholders. The development of the code took place at a time of contested views of directors' responsibilities and the code was framed with an investor focussed view. By this means the question of according rights to other stakeholders was avoided. In contrast, the key role of external relationships in the business model approach makes board responsibility for overseeing relationships inescapable. Filatochev et al. (2006) make it clear that independent directors have an important role to play in the process and may themselves be responsible for cementing important relationships through, for example, interlocking directorships.

Comparing these lists raises questions about the boundary line between corporate governance and management. As noted above, the rise of independent boards (CEOonly) may appear to consolidate this boundary, separating governance from management. In emphasising and facilitating the oversight role of the NED, this board structure (no longer unitary in practice) paradoxically places great power in the remaining executive board members, typically the $\mathrm{CEO}$ and $\mathrm{CFO}$, who now provide the link to the separate executive group. The impact of this shift in board structure has not been studied but there can be little doubt that board dynamics must have changed. The tasks involved in developing and sustaining the business model span both groups.

\section{Conclusion}

The argument of this paper is that, for a board of directors, corporate governance and sustaining and developing the company's business model are essentially the same thing. This is because the two systems entail the same goals and the same activities by the board. There are some advantages to adopting a business model approach to examining corporate governance because it integrates the conformance and performance activities of the board and it eliminates any perceived tension between what independent directors believe they have been appointed to undertake and the precepts of the UK Corporate Governance Code. The business model approach identifies an important omission from the UK Corporate Governance Code, namely the need for directors to take responsibility for the company's relationships with stakeholders other than shareholders, an area of significance in current discussions about corporate culture and ethics.

Viewing corporate governance through a business model lens offers a fresh perspective on the role of the board which provides improved integration between its strategic and compliance responsibilities. This can potentially enable a better 
understanding of how corporate governance contributes to the achievement of corporate objectives, rather than acting as a constraint.

Open Access This article is distributed under the terms of the Creative Commons Attribution 4.0 International License (http://creativecommons.org/licenses/by/4.0/), which permits unrestricted use, distribution, and reproduction in any medium, provided you give appropriate credit to the original author(s) and the source, provide a link to the Creative Commons license, and indicate if changes were made.

\section{Appendix: IASB (2010) management commentary: a framework for presentation (extract)}

\section{Nature of the business}

26 Management should provide a description of the business to help users of the financial reports to gain an understanding of the entity and of the external environment in which it operates. That information serves as a starting point for assessing and understanding an entity's performance, strategic options and prospects. Depending on the nature of the business, management commentary may include an integrated discussion of the following types of information:

(a) the industries in which the entity operates;

(b) the entity's main markets and competitive position within those markets;

(c) significant features of the legal, regulatory and macro-economic environments that influence the entity and the markets in which the entity operates;

(d) the entity's main products, services, business processes and distribution methods; and

(e) the entity's structure and how it creates value.

IASB (2010: 12).

\section{Relationships}

33 Management should identify the significant relationships that the entity has with stakeholders, how those relationships are likely to affect the performance and value of the entity, and how those relationships are managed. This type of disclosure helps users of the financial reports to understand how an entity's relationships influence the nature of its business and whether an entity's relationships expose the business to substantial risk.

IASB (2010: 14).

\section{References}

Anderson, R. (2015) Regulators talk risk. http://andersonrisk.com/2015/11/01/regulators-talk-culture/. Accessed November 7, 2015 
Beattie, V., \& Smith, S. (2013). Value creation and business models: Refocusing the intellectual capital debate. The British Accounting Review., 45(4), 243-254.

Demil, B., \& Lecocq, X. (2010). Business model evolution: In search of dynamic consistency. Long Range Planning, 43, 227-246.

Ezzamel, M., \& Watson, R. (1997). Wearing two hats: An analysis of the monitoring and control functions of Non-exectuive directors. In K. Keasey, S. Thompson, \& M. Wright (Eds.), Corporate governance: Economic, management and financial issues (pp. 54-79). Oxford: Oxford University Press.

Filatochev, I., Jackson, G., Gospel, H., \& Allcock, D. (2006). Key drivers of 'GOOD' corporate governance and the appropriateness of UK policy responses. London: Department of Trade and Industry.

Financial Reporting Council (FRC). (2014). UK corporate governance code. London: FRC.

Hampel Committee. (1998). Committee on corporate governance. Final Report. London, Gee.

Haslam, C., Tsitsianis, N., Andersson, T., \& Gleadle, P. (2015). Accounting for business models: Increasing the visibility of stakeholders. Journal of Business Models, 3(1), 62-80.

Hofstadter, D. (1980). Gödel, escher, bach. Harmondsworth: Penguin.

IASB. (2010). Management commentary: A framework for presentation. London: IASB.

IASB. (2015). Conceptual framework for financial reporting: Exposure draft. London: IASB.

IIRC. (2013). Business model background paper. http://integratedreporting.org/wp-content/uploads/2013/ 03/Business_Model.pdf. Accessed November 10, 2015.

Jensen, M., \& Meckling, W. (1976). Theory of the firm: Managerial behaviour, agency costs and ownership structure. Journal of Financial Economics, 3, 305-360.

Johnson, M., Christensen, C., \& Kagerman, H. (2008). Reinventing your business model. Harvard Business Review, 86(12), 57-68.

Joseph, J., Ocasio, W., \& McDonnell, M. (2014). The structural elaboration of board independence: Executive power, institutional logics, and the adoption of CEO-Only board structures in U.S corporate governance. Academy of Management Journal, 57(6), 1834-1858.

Kaplan, R., \& Norton, D. (1996). Using the balanced scorecard as a strategic management system. Harvard Business Review, 74(1), 75-85.

Langfield Smith, K. (2005). What do we know about management control systems and strategy? In C. Chapman (Ed.), Controlling strategy: Management, accounting, and performance measurement. Oxford: Oxford University Press.

Merchant, K. A., \& Van der Stede, W. A. (2012). Management control systems: Performance measurement, evaluation and incentives (3rd ed.). Upper Saddle River: FT Prentice Hall.

Nielsen, C., \& Roslender, R. (2015). Enhancing financial reporting: The contribution of business models. British Accounting Review, 47(3), 262-274.

Ocasio, W., \& Joseph, J. (2005). Cultural adaptation and institutional change: The evolution of vocabularies of corporate governance, 1972-2003. Poetics, 33, 163-178.

Osterwalder, A., Pigneur, Y., \& Tucci, C. (2005). Clarifying business models: origins, present and future of the concept. Communications of the Association of Information Systems, 16, 1-25.

Page, M. (2014). Business models as a basis for regulation of financial reporting. Journal of Management and Governance, 18(3), 683-695.

Roberts, J., McNulty, T., \& Stiles, P. (2005). Beyond agency conceptions of the work of the nonexecutive director: Creating accountability in the boardroom. British Journal of Management, 16(1), S5-S26.

Spira, L. F. (2001). Enterprise and accountability: Striking a balance. Management Decision, 39(9), 739-748.

Spira, L. F., \& Page, M. (2003). Risk management: The reinvention of internal control and the changing role of internal audit. Accounting Auditing and Accountability Journal, 16(4), 640-661.

Spira, L. F., \& Slinn, J. (2013). The cadbury committee: A history. Oxford: Oxford University Press.

Steiner, G., \& Miner, J. (1982). Management policy and strategy (2nd ed.). New York: NY Macmillan.

Stoner, J., \& Wankel, C. (1986). Management 3rd edn Englewood cliff. NJ: Prentice Hall.

Teece, D. (2010). Business models, business strategy and innovation. Long Range Planning, 43, $172-194$.

Tricker, B. (2012). Corporate governance: Principles, policies, and practices (2nd ed.). Oxford: Oxford University Press.

Wilson, R., \& Chua, W. F. (1993). Managerial accounting: Method and meaning (2 ed.). London: Chapman Hall. 
Zott, C., \& Amit, R. (2010). Business model design: An activity system perspective. Long Range Planning, 43, 216-226.

Zott, C., Amit, R., \& Massa, L. (2011). The business model: Recent developments and future research. Journal of Management, 37(4), 1019-1042.

Michael Page is Emeritus Professor of Accounting at the University of Portsmouth and holds visiting academic positions at Brunel University, Royal Holloway University of London and Southampton University. He researches and publishes on the Principles of Accounting and Corporate Governance.

Laura F. Spira is Emeritus Professor of Corporate Governance at Oxford Brookes University. She has published widely in the field of Corporate Governance. Her most recent book is The Cadbury Committee: a History (with Judy Slinn) Oxford: OUP. 